\title{
Теоретический анализ периодического усиления сигнала в волоконных лазерах
}

\author{
О.В. Штырина $^{*}$, И.А. Яруткина, А.С. Скидин, М.П. Федорук \\ Новосибирский государственный университет \\ *E-mail: olya.shtyrina@gmail.com
}

DOI: $10.31868 /$ RFL2020.177-178

В волоконных лазерах с распределенным усилением высокая энергия выходных импульсов достигается за счет многократного усиления сигнала в результате его последовательного распространения по ячейкам активного волокна внутри резонатора [1]. Лазеры с применением техники разгрузки резонатора являются примером таких систем. Однако для достижения желаемой энергии и мощности импульса необходимо оптимизировать параметры лазера, а также конфигурацию резонатора [2]. Поскольку число свободных параметров лазера растет с ростом числа усилительных ячеек, оптимизация таких систем требует больших вычислительных ресурсов. В связи с этим разработка новых эффективных теоретических аппроксимаций позволяет предсказывать оптимальные значения некоторых параметров лазерных систем.

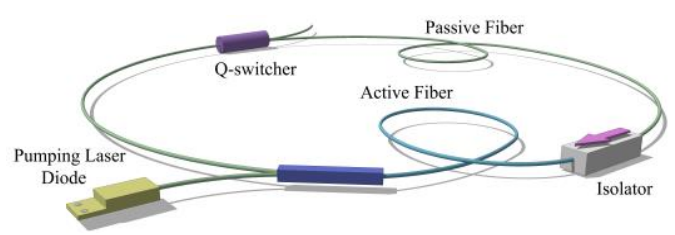

Рис. 1. Схема волоконного лазера с распределенным усилением.

Будем рассматривать резонатор с распределенным усилением как кольцевой резонатор с $n$ обходами активного волокна в течение времени обхода резонатора $T_{R}$ и с мультипликативными потерями (см. рис.1). В этом предположении динамика средней мощности зависит только он коэффициентов усиления $G_{i}$ $\left.\left(1<\mathrm{G}_{\mathrm{i}}<\exp (\mathrm{g}-\alpha) L_{i}\right)\right)$ и коэффициентов потерь $R_{i}\left(R_{l}=\ldots=R_{n-1} \neq R_{n-1} \cdot R_{\text {out }}<1\right)$. Здесь $i$ - число секций активного волокна, $L_{i}$ - длина i-й секции активного волокна, $\alpha$ - линейные потери, $g$ - коэффициент усиления малого сигнала. Тогда, общее усиление равно $G_{\text {total }}=\prod G_{\mathrm{i}}=1 / \prod \mathrm{R}_{\mathrm{i}}$. Для изучения динамики медленно меняющейся огибающей в волокне было использовано неконсервативное нелинейное уравнение Шредингера (см., например, [3]).

С целью нахождения распределения усиления вдоль лазерного резонатора будем использовать общий итерационный метод. Здесь набор коэффициентов $\left\{G_{i}^{0}=(q)^{i} / R_{n-1} ; q=R_{\text {out }}^{-\frac{2}{n(n+1)}}, 1 \leq i \leq n\right\} . \quad$ Верхний $\quad$ индекс $\quad$ для $\quad G^{j} \quad$ и $\quad P^{j}$ соответствует номеру итерации. Таким образом, получаем следующий итерационный процесс:

$$
\begin{aligned}
& \left\{P_{i}(0)^{j}=P_{\text {sat }}\left(\frac{g}{\alpha}-1\right)\left(C-\left(G_{i}^{j}\right)^{\alpha / g}\right) /\left(G_{i}^{j} C-\left(G_{i}^{j}\right)^{\alpha / g}\right)\right\}: \\
& \text { если }\left(P_{i}(0)^{j} G_{i}^{j} R_{i}<P_{i+1}(0)^{j}\right) \&\left(P_{i-1}(0)^{j} G_{i-1}^{j} R_{i-1}>P_{i}(0)^{j}\right) \Rightarrow G_{i}^{j} \text { переоценено, } G_{i}^{j+1}=G_{i}^{j} /\left(1+\varepsilon_{1}\right) \\
& \text { если }\left(P_{i}(0)^{j} G_{i}^{j} R_{i}>P_{i+1}(0)^{j}\right) \&\left(P_{i-1}(0)^{j} G_{i-1}^{j} R_{i-1}<P_{i}(0)^{j}\right) \Rightarrow G_{i}^{j} \text { недооценено, } G_{i}^{j+1}=G_{i}^{j} \times\left(1+\varepsilon_{1}\right) \\
& \text { иначе } \Rightarrow G_{i}^{j+1}=G_{i}^{j} ; 1 \leq i \leq n .
\end{aligned}
$$


Для данного итерационного процесса был использован следующий критерий сходимости: $\max _{1 \leq i \leq n}\left|P_{i}(0)^{j} G_{i}^{j} R_{i}-P_{i+1}(0)^{j}\right| / P_{i+1}(0)^{j}<\varepsilon_{2}$, где $\varepsilon_{1}$ и $\varepsilon_{2}$ принимают малые предопределенные значения.

Output power [mW]

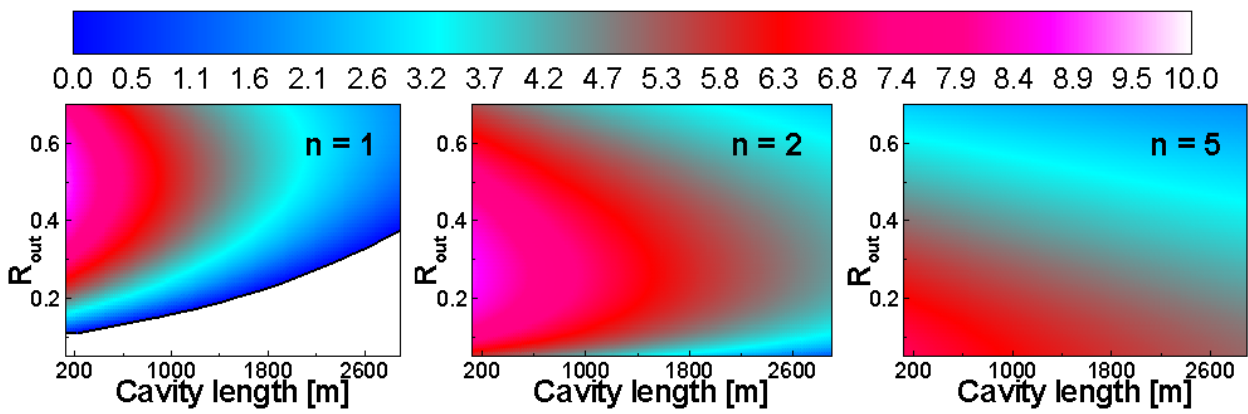

Рис. 2. Линии уровня выходной мощности в плоскости (длина резонатора, $R_{\text {out }}$ ) для различного числа секций активного волокна $(n)$.

Будем рассматривать эффективность усиления как отношение полученной выходной энергии к мощности накачки, необходимой для ее достижения. В этих терминах использование техники разгрузки резонатора позволяет повысить эффективность усиления. Увеличение выходной энергии происходит за счет практически неограниченной возможности компенсировать потери на модуляторе добротности. В системах с распределенным усилением баланс между усилением и потерями достигается при значительно бо́льших средних мощностях за счет отсутствия потерь на ответвителе в установившемся режиме при обходе по внутренней петле, что позволяет уменьшить величину общих потерь. Так, например, (см. рис. 2), при одинаковой частоте повторения в кольцевом волоконном лазере с длиной резонатора 2 км $(n=1)$ и волоконном лазере на основе техники разгрузки резонатора с пятью периодическими волоконными секциями $(n=5)$ по 400 м, выходная энергия во втором случае будет больше при меньших мощностях накачки и более широкой области устойчивой импульсной генерации.

Таким образом, системы с разгрузкой резонатора могут эффективно использоваться не только для активной синхронизации мод, но также для усиления сигнала. Достоинства таких систем связаны с их потенциальной возможностью компенсировать практически неограниченные потери на ответвителе, где уже при небольших значениях $n$ выходная энергия зависит от потерь между двумя последними активными элементами. При этом увеличение числа обходов периодических секций приводит к синхронизации мод, но негативно сказывается на выходной мощности сигнала.

Работа была выполнена при поддержке проекта РНФ №20-11-20040.

\section{Литература}

[1] A. Ivanenko, S. Kobtsev, et al. Opt. Express 24, 6650-6655 (2016)

[2] O. V. Shtyrina, I.A. Yarutkina, et al. IEEE Photonics J. 7, 1-7 (2015)

[3] B.G. Bale, O.G. Okhotnikov, S.K. Turitsyn, "Modeling and Technologies of Ultrafast Fiber Lasers," in Fiber Lasers (Weinheim: Wiley-VCH Verlag GmbH Co., 2012) 